\title{
A LEITURA DA PAISAGEM DA BAIXADA CAMPISTA: AS MATERIALIDADES E AS REPRESENTAÇÕES SOCIAIS REMANESCENTES ENTRE A PASSAGEM DO PERÍODO COLONIAL E IMPERIAL
}

\author{
La lectura del paisaje de la Bajada Campista: \\ Las materialidades y las representaciones sociales remanentes entre el paso del \\ período Colonial e Imperial
}

\author{
Raphael Neves da Conceição \\ Mestre em Geografia/UFF- Campos \\ rapha_nc@hotmail.com
}

Artigo recebido para publicação em 22/02/2018 e aceito em 14/04/2018

DOI: $10.12957 /$ tamoios.2018.32672

Resumo: O objetivo deste trabalho é apresentar uma leitura da paisagem da área de estudo denominada Baixada Campista. Localizada no município de Campos dos Goytacazes, Norte do Estado do Rio de Janeiro, considera-se que este recorte espacial estudado possui objetos, topônimos e elementos simbólicos representativos e advindos de diferentes períodos históricos e por isso pode vir a ser reconhecida como uma paisagem cultural. A análise da paisagem recairá sobre os elementos constituintes que estão presentes na paisagem atual, que representam diferentes agentes sociais modeladores desta paisagem, em particular aqueles vinculados entre a passagem do período Colonial e Imperial. Desse modo, a abordagem teórica adotada, encontra-se fundamentada nos autores da corrente da Nova Geografia Cultural, com ênfase nos estudos de Denis Cosgrove e Serge Moscovici. A periodização construída a partir da leitura da paisagem pode ser apresentada, sobretudo no período Colonial (XVIII) e Imperial (XIX).

Palavras-chave: Paisagem; Cultura; Baixada Campista; Campos dos Goytacazes.

Resumen: El objetivo de este trabajo es presentar una lectura del la paisaje del la área de estudio denominada Bajada Campista. En el municipio de Campos dos Goytacazes, al Norte del Estado de Río de Janeiro, se considera que este recorte espacial estudiado posee objetos, topónimos y elementos simbólicos representativos y provenientes de diferentes períodos históricos y por eso puede ser reconocido como un paisaje cultural. El análisis del paisaje recaerá sobre los elementos constituyentes que están presentes en el paisaje actual, que representan diferentes agentes sociales modeladores de este paisaje, en particular aquellos vinculados entre el paso del período colonial e imperial. De este modo, el enfoque teórico adoptado, se encuentra fundamentado en los autores del la corriente del la Nueva Geografía Cultural, con énfasis en los estudios de Denis Cosgrove y Serge Moscovici. La periodización construida a partir del la lectura del paisaje puede ser presentada, sobre todo en el período Colonial (XVIII) e Imperial (XIX).

Palabras clave: Paisaje; Cultura; Bajada Campista; Campos de los Goytacazes. 


\section{Introdução}

O objetivo deste trabalho consiste em realizar uma leitura da paisagem da área denominada Baixada Campista, constituída atualmente pelos distritos de Goitacazes, Mussurepe, Tócos, Santo Amaro e São Sebastião, recorte espacial situado no município de Campos dos Goytacazes (Norte Fluminense). A leitura da paisagem será feita a partir das reminiscências históricas e elementos simbólicos, bem como perceber as representações que se constituíram na paisagem por meio de objetos geográficos presentes na paisagem atual compreendendo que as materialidades existentes nesta área são compostas por objetos geográficos provenientes de diferentes períodos históricos.

A Baixada Campista tem sua formação territorial vinculada a diferentes periodizações, bem como a participação de distintos agentes hegemônicos em sua formação territorial desde o período Colonial Brasileiro (XVI). Em primeiro lugar, os Sete Capitães, que receberam parte destas terras, por meio de honras e mercês da Coroa Portuguesa pelos serviços prestados ao longo de anos, na luta contra os franceses e os índios Tamoyos no recôncavo da Guanabara; em segundo lugar, ordens religiosas, tiveram um papel fundamental sobre o controle do território, sobretudo couberam aos jesuítas e beneditinos primordialmente controlar o território. Estes receberam consideráveis glebas de terra na região; e por fim, os agentes da Coroa Portuguesa, os Viscondes de Asseca possuíam considerável controle sobre as terras arrendadas (REIS, 2011).

A Baixada Campista no período Colonial teve grande importância na pecuária, mas entre o final do período Colonial e na passagem do período Imperial a produção açucareira aumentou significativamente, à medida que se dissemina pela planície uma infinidade de engenhos centrais. No final do século XIX se verifica a substituição dos engenhos centrais pelas usinas e articulada a esta lógica de produção, a ferrovia.

As cerâmicas sobrepujaram paulatinamente a atividade açucareira desta área, fundamentalmente nos anos de 1970, e atualmente é o setor da economia que mais emprega na Baixada Campista.

A análise da paisagem atual recai sobre os elementos constituintes que representam diferentes periodizações e agentes sociais que modelaram a paisagem em análise. Consideramos que a área contém objetos e simbolismos representativos e advindos de diferentes períodos históricos, em particular do final do período Colonial (XVIII) e que se prolonga durante o período Imperial, isto é, vinculados ao período do auge da produção açucareira.

Diante do reconhecimento de sua importância histórica, observamos a carência de publicações referentes a esta área que contemplem a temática social. Acreditamos que o estudo da paisagem desta área pode vir a servir de fomento para futuras pesquisas. Consideramos ser importante pesquisar sobre as paisagens de um recorte espacial ainda pouco estudado no estado do Rio de Janeiro, a denominada Baixada Campista, que tem sua origem no período colonial brasileiro. Entretanto, esta atualmente, não tem o mesmo reconhecimento do passado, a não ser para os agentes locais. O estudo pode suscitar interesse com outras áreas do conhecimento, como aquelas referentes ao reconhecimento do patrimônio arquitetônico e cultural do Brasil.

A abordagem teórica para a leitura da paisagem deste recorte espacial está sob a ótica da Geografia Humanista e Cultural, advinda fundamentalmente dos anos de 1970 e 1980. Esta geografia, de Horizonte Humanista privilegia os aspectos essenciais sobre o desenvolvimento da paisagem, tal qual identificado os elementos simbólicos e lendo os seus significados contextualizados ao momento em que foram implantados sobre o espaço. Esta geografia é eclética (GOMES, 2012) pelo vasto leque de contribuições de 
variados autores, que não se limitam propriamente a ciência geografia, mas a história, as ciências sociais, a psicologia social, arquitetura entre outras. Apontamos alguns dos intelectuais utilizados na pesquisa: Santos (2012), Berque (2012), Cosgrove (2012), Moscovici (2003), Costa (2008); entre inúmeros pesquisadores que se dedicaram as temáticas referentes a memória e ao desenvolvimento econômico do Norte Fluminense.

\section{Os objetos geohistóricos da Baixada Campista}

Diversos objetos geohistóricos foram identificados ao longo da pesquisa na Baixada Campista, a saber: usinas de cana-de-açúcar, templos religiosos, estações ferroviárias, marco territorial e farol. Entretanto, o estudo em questão irá abordar o temário vinculado à produção açucareira.

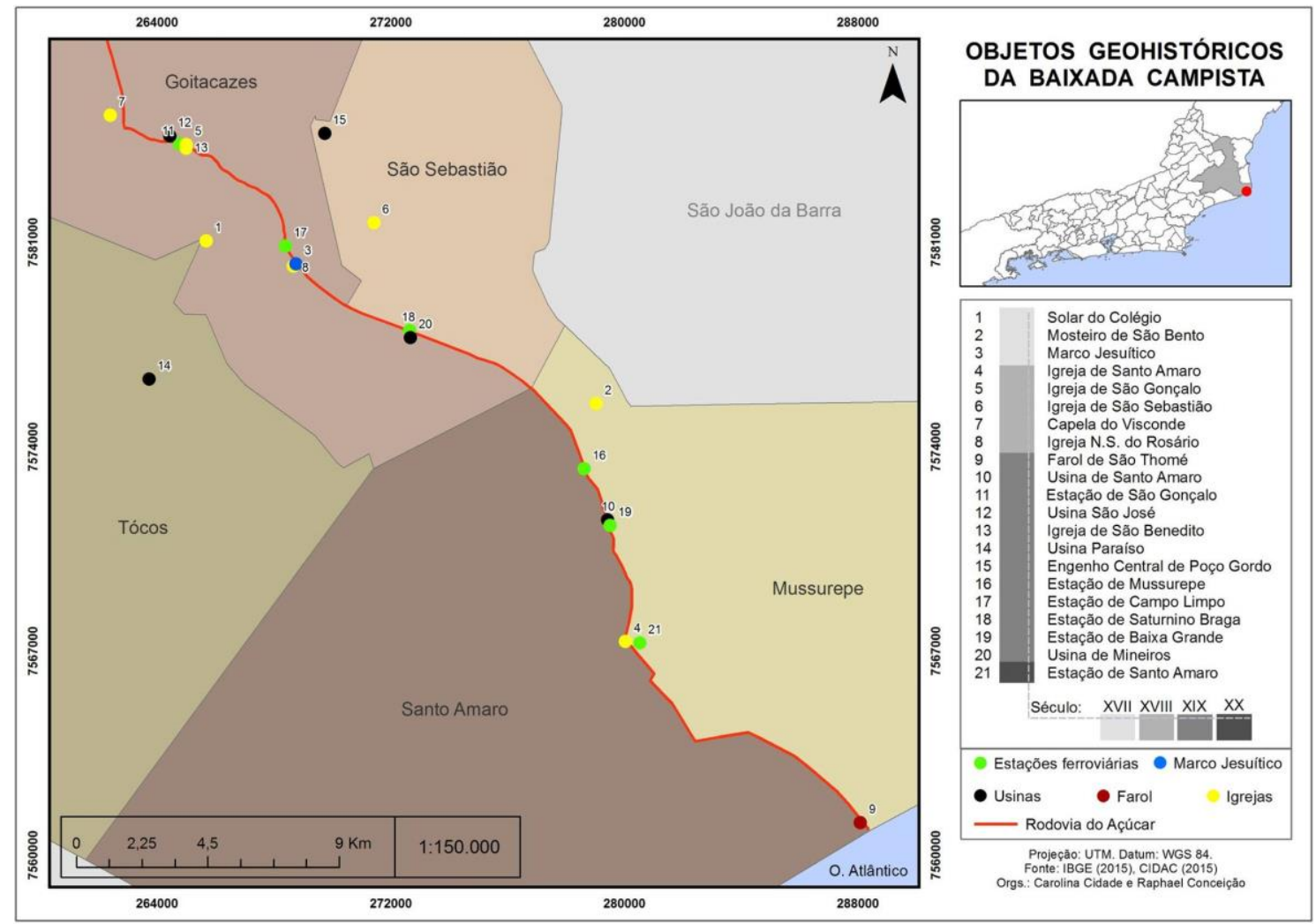

FIGURA 1: Mapa dos Objetos Geohistóricos da Baixada Campista. Fonte: IBGE/CIDAC, 2015 (Orgs.

Carolina Cidade e Raphael Conceição).

\section{O Engenho Central e as Ferrovias}

Em meados do séc. XVIII, a paisagem da Baixada Campista muda paulatinamente com a expansão da atividade canavieira, deste modo se deu a configuração da paisagem. Neste tempo podiam ser vistas, ao longo da planície, as chaminés das engenhocas. $\mathrm{O}$ grande interesse que os campistas dedicam à atividade canavieira se dá em virtude do solo fértil da região formada de solos de origem aluviares, e do regime de colonização que Portugal implantou sobre a colônia, utilizando o açúcar como um de seus principais produtos.

Assim, em 1799, contabilizou-se em Campos 378 engenhos de açúcar, que representavam 52\% dos engenhos instalados em toda a capitania do Rio de Janeiro (LARA, 1988). Nota-se neste momento, a importância regional e política que Campos obtivera com avultadas somas de exportação de açúcar ao exterior. Mas há um outro aspecto a ser ressaltado, visto que a maior parte da produção de açúcar concentrava-se nas usinas da freguesia de São Gonçalo (atual Baixada Campista). A esse respeito, a 
atividade canavieira se dissemina significativamente em Campos entre a passagem do período Colonial (XVIII) para o período Imperial (1822-1889). Embora a Baixada Campista se destacasse como importante produtora de açúcar, em 1828, verificou-se que o município era detentor no total de 700 engenhocas e engenhos. Neste período Campos passou por profundas transformações em sua paisagem; observa-se as chaminés dos engenhos com moendas de ferro e com ele os engenhos a vapor que começavam a aparecer na paisagem da planície (SILVA, 2004). Foi um momento de intensa revolução industrial em Campos, podia se verificar que a emergente indústria açucareira campista utilizava em seu parque industrial a tecnologia de patente inglesa e francesa. As engenhocas cederam lugar paulatinamente aos Engenhos Centrais com maior poder de produção e capitalização de recursos. Diante de tais mudanças, os donos das engenhocas acabaram por se transformar em fornecedores de cana para os grandes usineiros detentores do capital especulativo.

Os engenhos Centrais, que também podiam ser encontrados na Baixada Campista são resultantes dos processos de acumulação de capital pelo qual passa a região na passagem do final do período Colonial (XVIII) e perpassa durante o período Imperial. É neste contexto histórico que o engenho Central de Poço Gordo (distrito de São Sebastião) foi estabelecido na Baixada Campista no final do século XIX.

Por meio da representação cartográfica de 1909 intitulada: "Planta Geral dos Engenhos Centraes de Assucar" de autoria não identificada é possível inferir que a região Norte Fluminense era tomada por Engenhos Centrais.

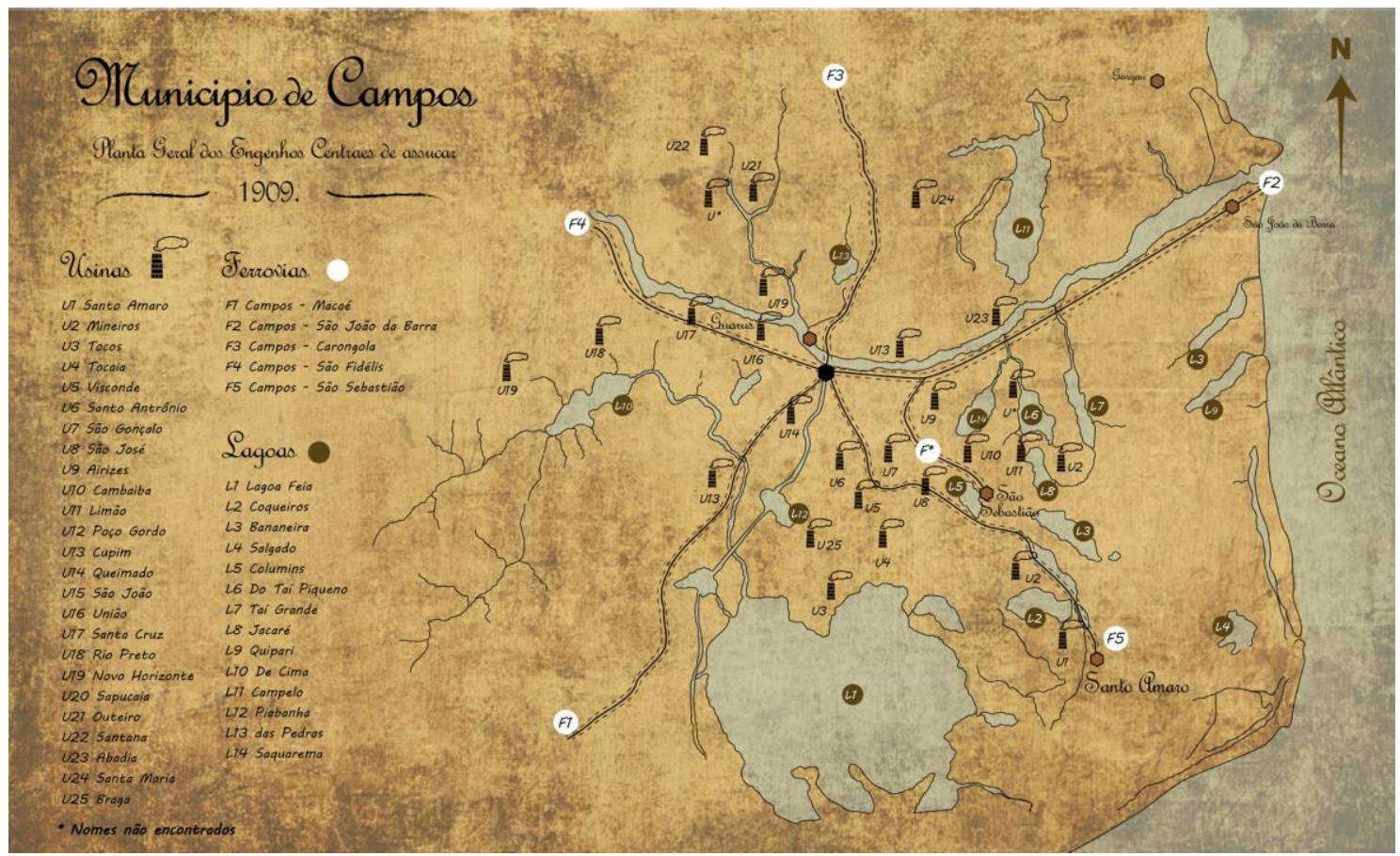

FIGURA 2: "Município de Campos. Planta dos Engenhos Centraes de Assucar, 1909. Fonte: Adaptado de autor desconhecido. Orgs. Murilo Desi e Raphael Conceição (2015).

A representação cartográfica acima demonstra a localização do engenho Central de Poço Gordo, situado no distrito de São Sebastião, em Poço Gordo. A representação aparece identificada como U12 (Fig. 2).

Nesta área do Norte Fluminense a edificação dos engenhos centrais foi estabelecida durante o Brasil - Império durante o século XIX, embora a representação dos "Engenhos Centraes de Assucar" conste de 1909. Nesta linha de raciocínio, é interessante notar ainda por meio da representação acima, que as usinas têm relativa proximidade em relação umas às outras, o que pode, de certa forma, ter provocado uma forte concorrência 
entre elas em relação ao fornecimento de cana. Cabe lembrar, que neste período, boa parte da área da Baixada Campista ainda era composta de brejais e lagoas, o que diminuía consideravelmente a área de produção. Somente com a chegada do DNOS (Departamento Nacional de Obras e Saneamento), na década de 1940, os brejais e lagoas foram dissecadas, e consequentemente as áreas de plantação de cana das usinas cresceram significativamente, aumentando, assim, sua produção. Neste cenário, a Baixada Campista se destacava como grande produtora de cana-de-açúcar da região Norte Fluminense.

Além da produção, cabe lembrar, que o período Imperial é marcado por estímulos e benesses econômicas dada aos usineiros do Norte Fluminense. No dizer de Lamego Filho (2007 [1946], p.159), "O Império fez o que era possível em sua época, a fim de auxiliar a sua produção do fluminense do norte, estimulando-o. A politicagem da $1^{\text {a }}$. República abandonou-o a braços com o forasteiro a cobrador de juros".

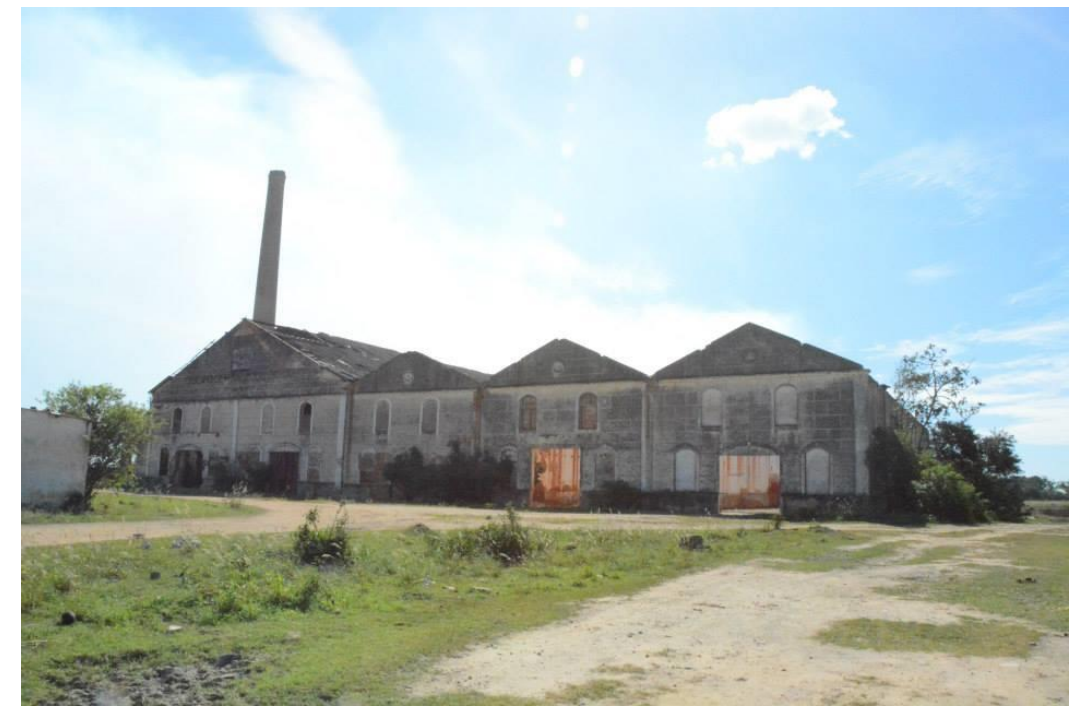

FIGURA 3: Ruínas do Engenho Central de Poço Gordo (Distrito de São Sebastião). Fonte: Acervo de Elis Miranda, 2015.

De acordo com Macedo e Silva (2012), os engenhos centrais foram constituídos a partir de subsídios governamentais e não poderiam utilizar de mão de obra cativa e teriam que adquirir a cana de produtores vinculados ao engenho. A fim de cumprirem o acordo institucional recebiam fiscalização.

De acordo com Santos (2012), em sua concepção sobre a configuração territorial, segundo o mesmo autor esta é dada pela história das relações sociais, pois os elementos que estão sobre o território, se tornam em uma produção histórica a partir das relações sócio-espaciais estabelecidas pelo homem. Um aspecto importante a ser considerado sobre a implantação dos objetos analisados nesta pesquisa se refere ao momento de implantação de cada um dos objetos geohistóricos. Neste sentido, Santos considera que "[...] toda a criação de objetos responde a condições sociais e técnicas presentes num dado momento histórico. Sua reprodução também obedece a condições sociais" (SANTOS, 2012, p. 68). As condições históricas de implantação dos objetos que se configuraram na paisagem neste caso correspondem a um momento histórico relacionado ao coronelismo proveniente do século XIX.

Neste contexto, durante o período Imperial, em especial, partir da década de 1870, observou-se a proliferação de ferrovias na região. A origem não está relacionada fundamentalmente ao transporte de passageiros, mas ao transporte de cana-de-açúcar para as usinas. A primeira linha férrea do Norte Fluminense estabeleceu-se na Baixada Campista, por meio da Estrada de Ferro de São Sebastião em 1873. Cabe ressaltar que as 
negociatas para implantação de ferrovias já vinham da década anterior por pressão de fazendeiros e comerciantes da Freguesia de São Sebastião (SOUSA, 1935).

A primeira delas, a Cia. Estrada de Ferro de Campos a São Sebastião foi criada em 1871, e sua primeira viagem foi no ano de 1873. A primeira viagem foi até a estação de São Gonçalo (atual Goitacazes). Ressaltando que apesar do ramal ser denominado Campos - São Sebastião, segundo Macedo e Silva (2012), a estação final era a de Santo Amaro, não tendo sido concluído o projeto de levá-la até São Sebastião, como previsto inicialmente.

O capital inerente a usina trouxe modificações na circulação da produção. As usinas, ao contrário dos engenhos centrais, eram derivadas de grande soma de capitais. A disseminação deste tipo de parque industrial pelo Norte Fluminense daria origem a uma extensa malha ferroviária. Como lembra bem Macedo e Silva (2012), as ferrovias se originaram no mundo e no Brasil sem uma visão de integração geral, de modo a atender aos interesses comerciais. As ferrovias que surgiram no Norte Fluminense, não fugiram a esta regra, pelo que vieram servir aos intuitos dos usineiros da região. Assim, disseminava-se pelo Norte Fluminense uma considerável malha ferroviária.

O poder proporcionado pela oligarquia do açúcar, ainda no Brasil - Império trouxera investimentos para a região, como a Estrada de Ferro Carangola e a Estrada de Ferro da Leopoldina. As engenhocas deram lugar aos engenhos centrais e usinas com patentes originárias da França e da Inglaterra (ALVES apud GERLANE, 2013). As estações ferroviárias ainda existentes na região são as marcas de um tempo vinculado ao período açucareiro.

Para Berque (2012), na paisagem, estão presentes essas marcas e matrizes. Neste sentido, as paisagens-marcas são impressas em parte da configuração da paisagem, visto que estas manifestações são concretas, e tem relação direta com a sociedade que as produziram, ou seja, estas paisagens expressam a lógica cultural de determinado tempo. De acordo com Berque (2012), a paisagem é uma marca, que representa uma determinada sociedade em dado momento, e continua enfatizando a paisagem como matriz, visto que, a partir dela há esquemas de percepção, concepção e ação, que por último dá origem a cultura, isto é, as relações homem-natureza realizadas no espaço.

A figura 4, a seguir, revela que os objetos edificados em momentos passados podem passar por diferentes re-funcionalizações. 


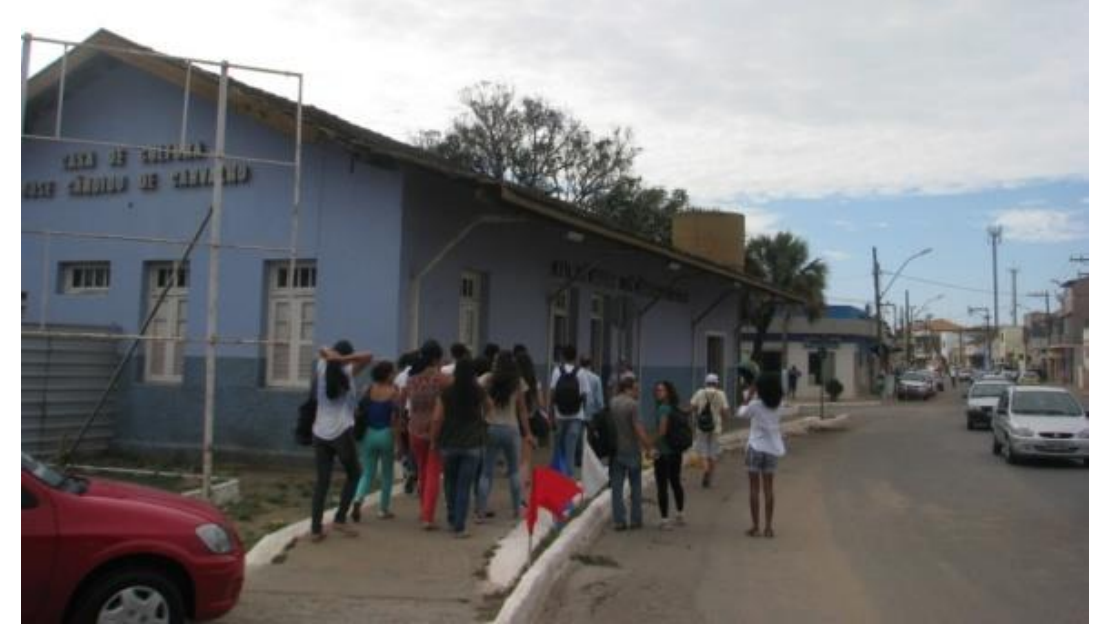

FIGURA 4: Antiga estação ferroviária de São Gonçalo, Atual casa de Cultura José Cândido de Carvalho. Fonte: Acervo pessoal, 2015.

Por meio de trabalho de campo realizado na antiga área da ferrovia de São Sebastião (Baixada Campista) foi possível identificar as refuncionalizações por que passaram as antigas estações ferroviárias que ali foram instaladas, entre o final do século XIX e início do século XX. É possível constatar que a estação de Mussurepe não desempenha atualmente função alguma, ao passo que a estação de Saturnino Braga e Campo Limpo ultimamente têm servido de domicílio; e por fim, a estação de Baixa Grande se transformou em unidade da Polícia Militar do Estado do Rio de Janeiro (PMERJ). Diante destas evidências, constata-se que há pouco zelo do poder publico pelo Patrimônio ferroviário, em especial do ramal de Campos - São Sebastião (Baixada Campista), visto que esta foi a primeira ferrovia vinculada ao parque industrial açucareiro estabelecida no Norte Fluminense, o que demonstra a importância para a configuração da paisagem atual da paisagem da Baixada Campista.

O transporte ferroviário era utilizado tanto para transportes de passageiros quanto para o transporte de cana de açúcar. De acordo com Lamego Filho (2007 [1945], p.158) as ferrovias do município perfaziam um total de $700 \mathrm{~km}$ de extensão, sendo que $300 \mathrm{~km}$ no território do município de Campos. Os outros $400 \mathrm{~km}$ integravam as áreas agrícolas adjacentes as usinas do Norte Fluminense. É curioso perceber que as usinas da Baixada Campista usufruíam destas linhas férreas em suas áreas de plantação para o escoamento de sua produção. O engenho central de Poço Gordo possuía $4 \mathrm{~km}$ de linha férrea, de São José $11 \mathrm{~km}$ e a de Paraíso $15 \mathrm{~km}$.

A ferrovia, posteriormente, foi vendida para a ferrovia Campos - Macaé, que em 1889 teria prolongado o trecho até o antigo distrito de Mineiros. Destaca-se ainda que em 1908, a ferrovia foi renomeada como ramal de Santo Amaro, e deste modo é adquirida pela Estrada de Ferro da Leopoldina; assim, Santo Amaro passa a ser sua última estação do ramal.

Ainda neste quadro regional, que abrangia a região Norte Fluminense, o poder e prestígio da aristocracia açucareira se mantiveram e se reconfiguraram, deste modo, a vila de São Salvador de Campos foi elevada à categoria de cidade em 28 de março de 1835, e definida como sede da comarca entre oito definidas. Segundo Fridman (2007), os principais critérios para a nova classificação de Campos no período imperial em comarcasede se justificavam pela gestão política, judiciária, fiscal e militar. No âmbito destes 
termos, estavam incluídos: a proximidade, centralidade militar, comunicação, rotas comerciais, contiguidade natural e sentimento de identidade com o lugar. Destacava-se a gestão política, citado pela autora, como crucial para o novo status quo que a região adquiriu.

Note que no Brasil - Império, a importância de Campos no contexto regional e nacional se expressa pelo poder dos Barões do Açúcar. Neste momento histórico, os engenhos de cana-de-açúcar fazem parte de novo contexto histórico representado pela sua dispersão no Norte Fluminense. A fim de exemplo, os engenhos em 1827 são em número de 700, destes, apenas um a vapor. Em 1852, os engenhos a vapor chegam à totalidade de 52, em 1872, à totalidade de 113, e por fim, em 1881 os engenhos a vapor chegam à soma de 125 (LAMEGO FILHO, 2007[1946]; ALVARENGA apud FRIDMAN, 2007). A tecnologia do engenho a vapor e a passagem para modernas usinas com maior capacidade de produção foram o reflexo da emergência da aristocracia local.

De acordo com Penha et al. (2012, p. 27), a relação entre os grupos sociais articulada com a atividade açucareira estava estruturada em senhores de engenho e barões do açúcar, esta última designação seria oriunda do período Imperial. Estas sociedades emergentes de burgueses do açúcar estavam ao mesmo tempo inseridas em atividades financeiras conectadas à escala local, nacional e internacional. Estas articulações de escalas se evidenciavam no tráfico de escravos e em empréstimos aos senhores de engenho. Em segundo lugar, o clero exerceu grande influência na vida social por possuir vastas propriedades agrícolas da Baixada Campista. E por último, a grande mão de obra cativa negra empregada no processo de produção (PENHA et al., 2012).

De acordo com Piquet (2004), em meados do século XX havia uma estrutura social bem nítida na região, em primeiro lugar, os usineiros com poder político e capital; em segundo, os fornecedores de cana, subalternos aos usineiros; em terceiro, os pequenos proprietários, arrendatários ou parceiros, que plantavam cana ou vendiam seus serviços às usinas ou para outras atividades; e por último, o proletariado temporário ou fixo.

A paisagem da área urbana era marcada pelos solares em que a nobreza rural vivia, isto é, em suntuosos edifícios nas cidades. A "nova classe empresária" era composta por barões do açúcar e do café, que exerciam diferentes funções, tais como, comerciais e bancárias e possuíam nas fazendas volumosos números de escravos. Diversas instituições em importância econômica já faziam parte do cotidiano desta aristocracia no período imperial, a saber: Caixa Econômica de Campos (1834), Banco Comercial e Agrícola do Rio de Janeiro, Casa Bancária Caldeira (1859), Banco de Campos (1863) e a Sociedade União Artística Beneficente.

A classe da elite imperial, constituída por coronéis, administrava os engenhos centrais e usinas, que por sua vez possuíam terras arrendadas a pequenos e médios agricultores, e recebiam vultosos subsídios governamentais, e mão de obra barata. Segundo Cardoso ([2006), a multiplicidade de coronéis no Império está relacionada ao grau de parentela, com formação de alianças e associações econômicas para dar andamento a interesse de determinados grupos políticos. O coronelismo tem sido entendido como uma forma específica de poder político brasileiro, que floresceu durante a Primeira República e cujas raízes remontam ao Império; assim, nota-se que boa parte dos municípios neste período eram semelhantes a feudos políticos que se transmitiam por herança não configurada legalmente, mas que existia de maneira informal (CARDOSO, 2006). De onde vinha este título marcial? Haviam se originado dos títulos da Guarda Nacional; criada pouco depois da independência para defender a Constituição, auxiliar na manutenção da ordem prevenindo as revoltas, promover o policiamento regional e local (CARDOSO, 2006). 


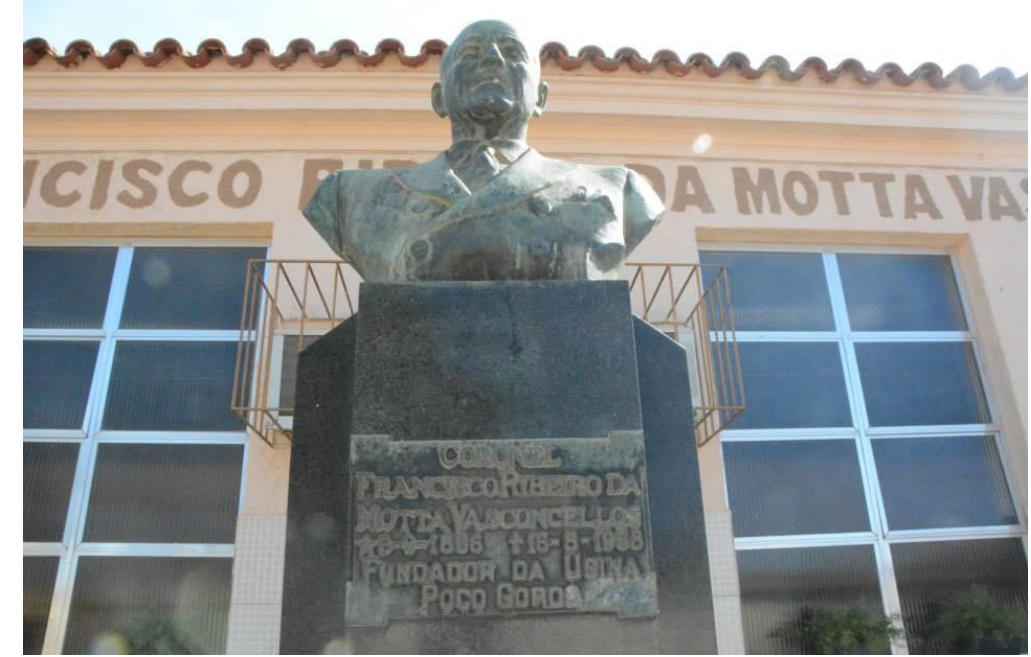

FIGURA 5: O fundador do engenho Central de Poço Gordo: Coronel Francisco Ribeiro da Mota Vasconcellos. Fonte: Elis Miranda, 2015.

No caso da Baixada Campista, a fotografia do busto do Coronel Francisco (FIG. 5), localizada no distrito de São Sebastião (Poço Gordo), identifica este período da alternância do poder entre os denominados coronéis. O coronel Francisco Ribeiro da Mota Vasconcellos é um desses "senhores de engenho", que usufruiu das benesses concedidas e compradas no período Imperial. De acordo com Pinto (1995), o Coronel Vasconcellos foi o fundador do Engenho Central de Poço Gordo, bem como um dos proprietários da Usina de São José. Seu filho foi proprietário da Usina de São Gonçalo Vasconcellos no distrito de São Gonçalo (atual Goitacazes). Cabe ressaltar, que a dita Usina de São José, por anos seguidos, viria a bater recordes de produção entre a usinas da Baixada Campista (SILVA, 2004).

De um modo geral, ser o "coronel” trazia um significado além da insígnia em si. Significava além de ser o dono do engenho central ou usina, ter influência política na municipalidade. A concretização do poder desempenhado pelos coronéis se disseminou na materialização de fixos que fazem menção aos mesmos, como escolas, bustos e ruas em geral.

Em verdade, o aspecto político é o que mais chama a atenção, visto que se observa as diferentes facetas que compõe a figura do coronelismo na região; não é, porém, o único, e sim entre muitos (CARDOSO, 2006). Assim, o poder político é medido através da quantidade de votos de que dispunham um chefe local ou regional no momento das eleições.

Existiriam, então, no Brasil coronéis de vários graus, desde o pequeno coronel, que não dominava senão uns duzentos eleitores, até o grande coronel, o mandão nacional, com outros níveis de coronel abaixo dele. A quantidade de graus da estrutura coronelística variava de região para região (CARDOSO, 2006). O coronelismo açucareiro, presente neste período histórico na Baixada Campista, em especial, guardaria singularidades, como o favorecimento por benesses vindas do Estado, bem como os empréstimos renovados, mesmo que o calote aos cofres da União fosse dado como inevitável.

Embora o poder desta classe rural capitalista se expressasse na cidade, por meio da reprodução do capital na arquitetura francesa na área central de Campos, sobretudo, por meio do capital bancário e comercial, ressalta-se, entretanto, que foi no campo onde se originou a fonte destes preciosos recursos provenientes da atividade sucroalcooleira, concentrada principalmente pela Baixada Campista. Diversas usinas seriam edificadas nesta área, favorecida pelo capital e prestígio dos Coronéis e Barões do açúcar. Consequentemente, o poder dos Barões do açúcar provenientes do período Imperial se 
deslocou com o tempo para o período Republicano (1889-1930), por meio de representações sociais concretizadas em atos.

Sobre as representações sociais, Moscovici (2003), pontua que estas se impõem sobre os indivíduos antes mesmo da habilidade de pensar, bem como são moldadas pelas tradições passadas de geração para geração, o que para Moscovici (2003, p. 36), provém "[...] de uma tradição do que deve ser pensado". As representações são produtos transmitidos, elaboradas e reelaboradas conforme o contexto histórico-social, assim, como as correntes epistemológicas que implantaram no decorrer do percurso paradigmas que vez ou outra eram refutados ou readaptados.

É possível notar que a mentalidade representativa do coronelismo, presente de modo geral em Campos, vai além do período Colonial, encontrando permanências no modo de agir e pensar das gerações de usineiros da primeira metade do século XX. Neste contexto, é curioso notar, que uma notícia veiculada na Folha do Comércio de seis de janeiro de 1938, em que os usineiros de Campos pareciam disputar quem construiria a maior chaminé de usina já vista, em que o título traz os seguintes dizeres: "O ponto mais culminante de Campos estará, brevemente, na grande torre em construção da Usina do Queimado".

\footnotetext{
Qual é o ponto mais culminante de Campos? Até a pouco tempo diziam uns ser a Cathedral Campostina, com 45 metros até as ditas cruzes que se vêem ao alto de suas bellas torres. Ultimamente levantou-se a grande torre da antenna da Rádio Cultura de Campos, superando as agulhas da Cathedral.

Agora, no entanto, uma nova altura vae imperar.

Será ella a da formidável Usina do Queimado, da importante firma Julião Nogueira \& Irmão, já está fazendo levantar, em substituição à antiga, que já não satisfazia às exigências da fábrica já agora tão ampliada.

A nova torre foi iniciada no dia 29 de novembro, e o seu custo estará entre 120 e 150 contos de réis devendo contar com cerca de 60 metros de altura. A sua base tem 4,60 de largura e a sua boca terá 2,60.

Estando na linha aeronáutica será a grande torre iluminada por trez poderosos reflector especiaes o que dará um aspecto magnificente à bella chaminé, que será pintada em anneis brancos e vermelhos.

A nova obra que levam a effeito os proprietários da moderna usina de açúcar, é mais uma afirmação do espírito do progresso que anima a modelar organização industrial que tanto nos honra.
}

Por meio da notícia veiculada pela Folha do Comércio, é possível ter noção da dimensão de poder que os grupos hegemônicos locais vinculados ao açúcar representavam. Estes grupos hegemônicos procuravam demonstrar poder e opulência por meio de seus bens e títulos nobiliárquicos. Percebemos também, através da mesma notícia, como funcionava a mentalidade da mídia local e dos usineiros ainda no final da década de 1930. A notícia representa a importância da torre da usina como um símbolo de status quo dos usineiros daquele período. Em verdade, a magnitude da torre, neste caso, não indicava simplesmente maior potencialidade na produção de açúcar, além disso, procurava expressar o poder e opulência dos agentes hegemônicos modeladores do espaço em questão. Neste sentido, a concretude do poder expresso na paisagem era disseminada pela região no período açucareiro por meio das chaminés ou das torres dos engenhos centrais e usinas de cana-de-açúcar, em especial da Baixada Campista.

De acordo com Cosgrove (2012), nas paisagens se manifestam estes códigos simbólicos representados pelas sociedades de classe. Neste contexto, a ideologia tem um papel crucial, porque reproduz o espaço para que mantenha a dominação dos grupos sociais hegemônicos. Logo, na ação humana se manifesta a produção e manutenção das paisagens simbólicas. 
Outro ponto fundamental, que chama a atenção na forma de organização que pode ser observado nas paisagens originadas das usinas, é a legitimação do controle que os usineiros exerciam sobre o proletariado. Ainda com resquícios da representatividade dos coronéis do período Imperial, estes usineiros construíam casas para o proletariado em área adjacente ao parque industrial da usina.

Diferentes usinas adotaram o mesmo método de organização racional de seu parque industrial na Baixada Campista, como as usinas de Paraíso e São José, isto é, estavam entre as usinas de maior produção de sacas de açúcar do município. A racionalização da produção resultou na construção de inúmeras casas padronizadas para os funcionários, conhecida popularmente entre a população local como "casinhas". Nestes lugares semelhantes a pequenas cidades, é o lugar do cotidiano da vida social destes trabalhadores, onde foram instaladas igrejas, cartórios, mercearias e açougues, onde o usineiro além de administrador era o "prefeito" da vila na condição de provedor, por seu vínculo com a elite política do município.

Mas, segundo Silva (2004), alguns usineiros em 1952 costumavam cobrar pelo uso das casas. Nas palavras de Silva (2004, p. 261): "Usineiros cobram até 27\% do salário de aluguel das casas das usinas ocupadas pelos trabalhadores, segundo a denúncia de Amaro Soares, vereador e presidente dos Trabalhadores na Indústria do Açúcar, isso em janeiro de 1952".

Sabe-se que as casas em que os trabalhadores habitavam ficavam bem próximas às usinas (FIG. 6). Se por um lado, representava facilidade ao trabalhador em sua locomoção ao trabalho, por outro, indicava por parte do capitalista controle de sua força de trabalho.

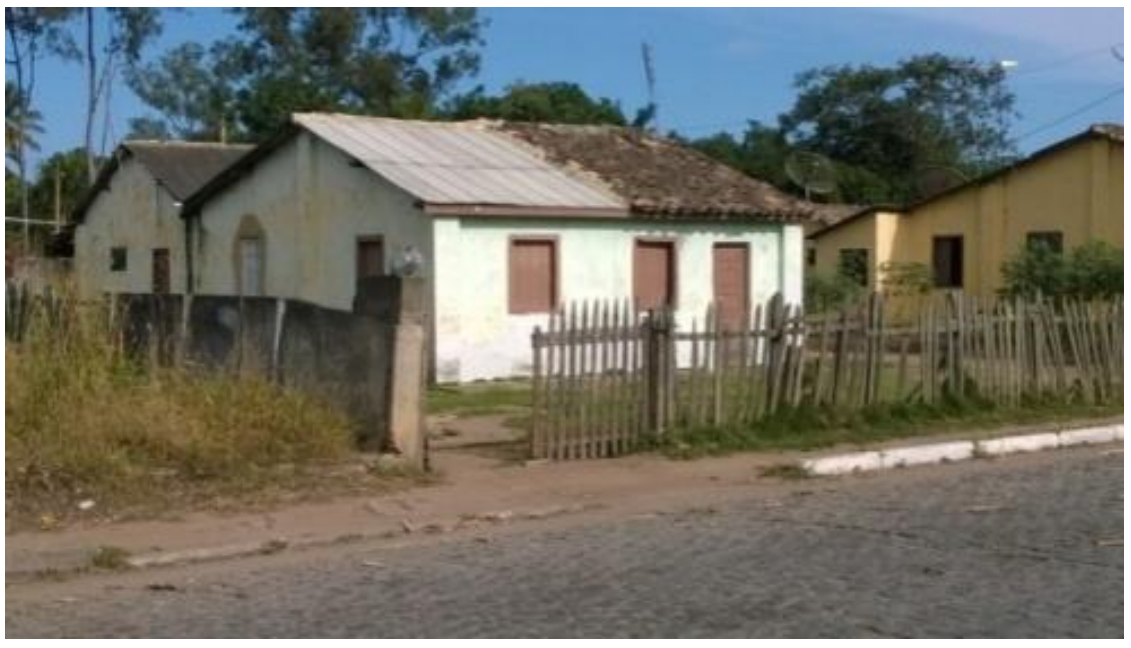

FIGURA 6: Casas da Usina Paraíso. Fonte: Acervo Pessoal, 2014.

Existia ainda outro ponto importante a respeito das casas: o sentimento de agradecimento que o trabalhador devia ao "dono da usina" por ter aquela casa (FIG. 6). Este sentimento de gratidão era utilizado ao mesmo tempo pelos usineiros como forma de legitimar a subordinação do proletariado ao mandonismo, o que de certo modo, se configura em uma permanência e herança advinda do período Imperial para a primeira metade do século XX.

A casa do Coronel instalada próxima ao seu lugar de trabalho fazia parte desta forma de organização do parque industrial das usinas Baixada Campista. Foi constatado que a proximidade da casa do coronel próxima a usina em outras usinas, na usina de Santo Amaro (Baixa Grande) e no engenho central de Poço Gordo (Poço Gordo).

Grande parte das usinas campistas estava localizada na Baixada Campista. As usinas da região batiam ano a ano, recordes em produção. A área de maior produção de 
açúcar do município ainda se concentrava na Baixada Campista (SILVA, 2004, p. 71265). A usina de São José (FIG. 7), por exemplo, por anos seguidos está entre as usinas de maior produção de açúcar. Silva $(2004$, p. 265) assinala que "São José continua sendo a de maior produção em Campos, conseguido 600 mil sacas na safra de 56, com a safra continuando até fevereiro de 57'. A usina, identificada por Osório Peixoto Silva, estava até 2014 com sua produção açucareira ativa, porém teve sua produção direcionada para a Usina de Sapucaia que estava desativada.

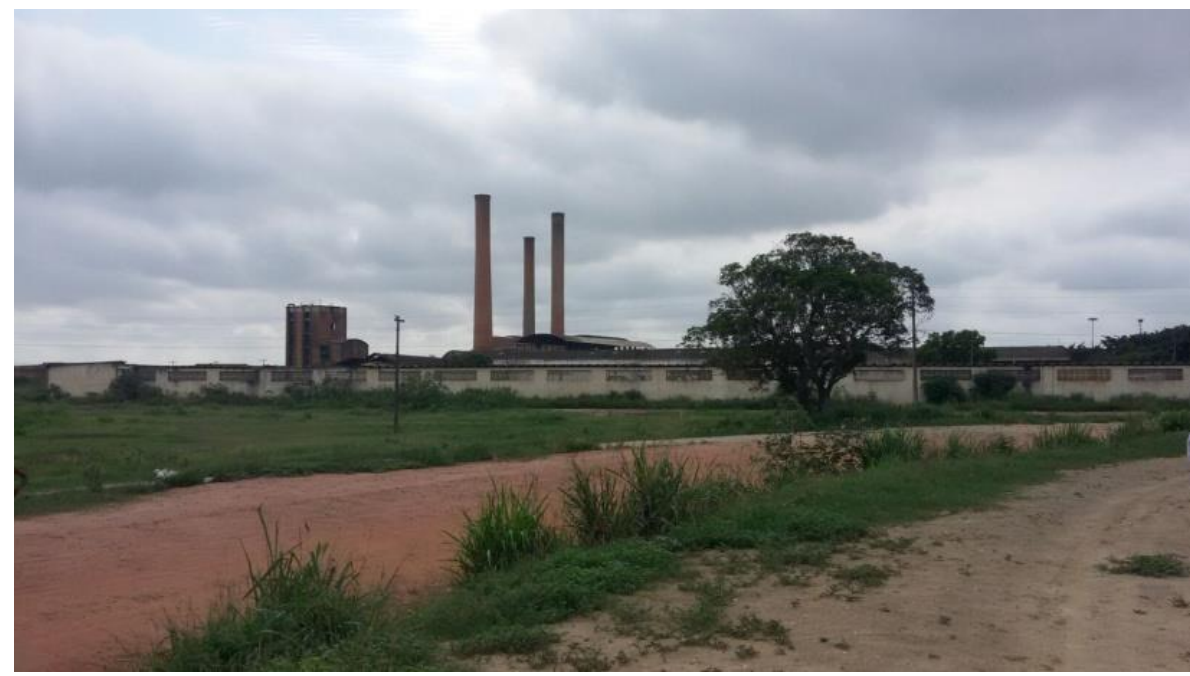

FIGURA 7: Usina de São José. Fonte: Acervo Pessoal, 2015.

A maior parte das usinas da Baixada Campista foram instaladas antes da virada do século XX, a título de exemplo temos o engenho de Mineiros, que posteriormente se adjetivou em usina na virada do século XIX para o século XX. De acordo com Lamego (2007, p. 115), a partir de 1875 a respectiva usina teria se estabelecido na região juntamente com as de São José, do Limão e do Colégio.

A chaminé da usina de Mineiros deu lugar a atividade cerâmica instalada no mesmo local, ressalta-se que esta atividade econômica é a mais importante da Baixada Campista atualmente. A chaminé foi edificada em 1934, porém a usina se originou no fim do século XIX.

As ruínas do parque industrial açucareiro são de extrema importância para a memória do Brasil e do município, pois se percebe que se dá maior importância à preservação do patrimônio material referenciado as igrejas católicas da região em detrimento do parque açucareiro disseminado pela Baixada em especial. Ao analisar o livro de Tombo dos Bens Históricos, Arquitetônicos e Culturais online, não se verificou o tombamento sistemático dos bens materiais relacionados às usinas e engenhos centrais, bem como as estações ferroviárias. As únicas referências encontradas no site foram o tombamento da chaminé da usina de Santo Antônio e da casa da sede nas dependências da usina do Queimado. Diante destas informações presentes nos órgãos oficiais da municipalidade, pode se verificar que ainda não se tem dado a devida importância ao parque industrial açucareiro e aos desdobramentos de sua organização espacial, visto que este se expressou em importância na paisagem por meio de simbolismos e representações, em especial na Baixada Campista, uma região onde esta atividade se representou na paisagem e mentalidades dos indivíduos e diferentes grupos sociais da região.

Para Costa (2008, p.149), é essencial considerar o Patrimônio Cultural que ainda não foi institucionalizado pelo poder público com elevado potencial arquitetônico. As paisagens vernáculas trazem consigo seu próprio valor simbólico, portanto, nas palavras do autor "[...] permite identificar um sujeito oculto da paisagem, ou seja, o modo de 
produção que impregna as práticas sociais e faz surgir ou organizam territórios valorizados ou repugnantes" (COSTA, 2008, p. 149).

\section{Conclusão}

Os objetos geohistóricos vinculados ao açúcar na Baixada Campista, pelo que se constatou na pesquisa realizada são inúmeros. O esquecimento do Patrimônio vinculado ao Parque Açucareiro traz grandes prejuízos a sociedade brasileira, tais como a perda da memória coletiva e a acentuada deterioração deste parque industrial rico em representações vinculada em grande parte ao Coronelismo proveniente do século XIX. A falta de zelo pela sociedade por este Patrimônio Histórico e Cultural pode vir a servir de justificativa para sua destruição e deterioração. Neste sentido, há que se reconhecer por meio da pesquisa realizada, que os objetos geohistóricos relacionadas ao período açucareiro trazem fortes simbolismos e permanências impregnadas de significados que ainda permanecem no cerne da população local. Logo, as representações sociais advindas do período açucareiro se refletem na mentalidade e nas práticas sociais dos indivíduos e dos grupos sociais desta área. Deste modo, como bem nos lembrou Costa (2008, p. 150): "[...] A paisagem revela ainda a realidade do espaço em um determinado momento do processo. O espaço construído ao longo do tempo de vida das pessoas, considerando a forma como vivem, o tipo de relação que existe entre elas e que estabelecem com a natureza $[\ldots] "$.

Consequentemente, as marcas e vestígios de um passado vinculado às usinas de cana-de-açúcar estão presentes em considerável parte da paisagem do município, em especial na Baixada Campista. Outrossim, as marcas matrizes nas ruínas que a decadência econômica deixaram durante o desenrolar dos anos de 1970 e 1980 que assolaram o setor canavieiro em Campos dos Goytacazes. Portanto, é necessário uma política pública que vise a preservação do Patrimônio Material vinculado ao parque industrial açucareiro da Baixada Campista.

Neste sentido, acreditamos que o estudo da paisagem desta área pode vir a servir de fomento para futuras pesquisas. Consideramos ser importante pesquisar sobre as paisagens de um recorte espacial ainda pouco estudado no estado do Rio de Janeiro, a denominada Baixada Campista, que tem sua origem no período Colonial brasileiro. Entretanto, esta atualmente, não tem o mesmo reconhecimento do passado. O estudo pode suscitar interesse com outras áreas do conhecimento, como aquelas referentes ao reconhecimento do patrimônio arquitetônico e cultural do Brasil.

\section{Referências:}

BERQUE, Augustin. Paisagem-marca, paisagem-matriz: elementos da problemática para uma geografia cultural. In: CORREA, Roberto Lobato; ROSENDAHL, Zeny (Orgs.). Geografia Cultural: uma antologia. Rio de Janeiro: Ed. UERJ, 2012.

BR. RJ . APMC . JC. Folha do Comércio, 6 de Janeiro de 1938. Folha do Comércio, Arquivo Público Municipal Waldir Pinto de Carvalho: coleção de Jornais Campistas.

CARDOSO, Fernando Henrique. O coronelismo numa interpretação sociológica. In: FAUSTO, Boris; HOLANDA, Sérgio Buarque de. (Orgs.). O Brasil Republicano: estrutura de poder e economia (1889 - 1930). 8. ed. Rio de Janeiro: Bertrand Brasil, 2006.

COSGROVE, Denis. A geografia está em toda parte: cultura e simbolismo nas paisagens humanas. In: CORREA, Roberto Lobato; ROSENDAHL, Zeny (Orgs.). 
Geografia Cultural: uma antologia. Rio de Janeiro: EdUERJ, 2012.

COSTA, Otávio. Memória e paisagem: em busca do simbólico dos lugares. Espaço e Cultura, UERJ, edição comemorativa. 1993-2008.p. 149-156.

FRIDMAN, Fania. Cidade e o campo no Brasil imperial. O caso da Província do Rio de Janeiro. In: Congresso Latino-americano de História Econômica, 1., 2007, Montevideu. Anais... Montevideu: Associação Uruguaia de História Econômica, 2007.

GOMES, P.C.C. Geografia e modernidade. 6. ed. Rio de Janeiro: Bertrand Brasil, 2012.

GERLANE, B. R. M. Imagens Urbanas, Patrimônio Cultural e Memória Social no Brasil Contemporâneo: estudo de caso das cidades de Campos dos Goytacazes e Vassouras no Estado do Rio de Janeiro. 2013. 251f. Dissertação (Mestrado em Memória Social) - Universidade Federal do Estado do Rio de Janeiro (UNIRIO), Departamento de História, 2013. Rio de Janeiro, 2013.

LAMEGO FILHO, Alberto Ribeiro. O Homem e o Brejo. Rio de Janeiro: IBGE, 2007.

LARA, Silvia Hunold. Campos da Violência: Escravos e Senhores na Capitania do Rio de Janeiro, 1750-1808. Rio de Janeiro: Paz e Terra, 1988.

MACEDO, Nylson; SILVA, Leonardo de Vasconcelos. A Ferrovia Agrícola de Quissaman e suas conexões regionais. Quissamã (RJ): Prefeitura de Quissamã, 2012.

MOSCOVICI, Serge. Representações Sociais: investigações em psicologia social. Petrópolis: Vozes, 2003.

PENHA, Giordiano Henrique Corrêa da [et.al.]. Notas sobre a fundação do município de Campos dos Goytacazes. Campos dos Goytacazes, RJ: FCJOL, 2012.

PIQUET, R. Norte Fluminense: mudanças e incertezas na era do petróleo. Revista de Desenvolvimento Econômico, Salvador, v. 6, p. 27-35, 2004.

REIS, M. M. do C. Manuscritos de Manoel Martins do Couto Reis 1785: descrição geográfica, política e cronográfica do distrito dos Campos dos Goytacazes. 2. ed. rev. atual. Campos dos Goytacazes: Fundação Cultural Jornalista Osvaldo Lima; Rio de Janeiro: Arquivo Público do Estado do Rio de Janeiro, 2011.

SANTOS, M. A natureza do Espaço: técnica e Tempo, Razão e Emoção. São Paulo: Editora da Universidade de São Paulo, 2012.

SILVA, Osório Peixoto. 500 anos de Campos dos Goytacazes. Campos dos Goytacazes: Fundação Cultural Jornalista Oswaldo Lima, 2004.

SOUSA, Horácio de. Ciclo Áureo - a história do $1^{\circ}$ Centenário da cidade de Campos (1835-1935). Campos dos Goytacazes: Artes Gráficas - Escola de Aprendizes Artífices, 1935 . 


\section{Referências Eletrônicas:}

Busto de Francisco Ribeiro da Mota Vasconcellos. Disponível em: <http: www.culturacamposritombo003.blogspot.com.br/2012/busto-de-francisco-ribeiro-damota.html?m=1>. Acesso em: 17 out. 2015.

Casa sede da usina do queimado usina. Conforme a resolução $n^{\circ} \cdot 005 / 2013$. Disponível em: $<$ http://www.culturacamposrjtombo005.blogspot.com.br/2014/11/casa-sede-dausina-do-queimado-usina-do.html?m=1>. Acesso em: 17 out. 2015.

Centenário da Independência do Brasil; álbum do Estado do Rio de Janeiro, 1922. [Organizado por Clodomiro R. de Vasconcellos]. [Rio de Janeiro]: Pimenta de Mello, 1922], [234p.]: foto e il. (foto e estão com alguma cor); (Fotografia de Daniel Ribeiro), (Folha de rosto com emblema do Estado do Rio de Janeiro); Efetuado durante à Presidência do Estado do Rio de Janeiro pelo Dr. Raul de Moraes Veiga. Disponível em:http://docvirt.com/docreader.net/DocReader.aspx?bib=bib_redarte\&pagfis=5139\&p esq >. Acesso em: 14 dez. 2015.

Estações Ferroviárias. Disponível em: $<\mathrm{http}: / /$ www.estacoesferroviarias.com.br/efl_rj_litoral/efl_linha_litoral.htm>. Acesso em: 7 dez. 2015. 